\title{
The evolution of mental handicap services in the Yorkshire Region and the Association of Yorkshire Regional Consultants in Mental Handicap
}

\author{
Douglas A. Spencer, Consultant Psychiatrist, Meanwood Park Hospital, Tongue Lane, \\ Leeds
}

At the present time, changes in the NHS provision for people with mental handicaps mark the end of one era and the beginning of another. The Yorkshire Region is seeing a far-reaching change from a previously regionally organised hospital system to district-based services. It is a time to take stock of what has existed before it is altered completely.

\section{Mental handicap hospital services in the Yorkshire region}

Between 1948 and 1974 services for mental handicap in the Leeds, from 1974, Yorkshire, region were organised on a basis of 'Subregional Admission Bureaux'. The number of these bureaux varied from four to five at different times. Originally each bureau consisted of a large number of contiguous local government districts, rural districts, urban districts, metropolitan boroughs and county boroughs, with a total population of from 500,000 to $1,000,000$ or more. The bureaux covered extensive geographical areas.

Each bureau was self-sufficient and had its base in a large 'comprehensive' mental handicap hospital of over 300 beds which could receive most types of patients, children and adults, short-stay and longstay, behaviourally disordered and highly dependent. In addition, each bureau comprised a variable number of smaller hospitals. These could be divided into

(a) those of medium size with 100 to 200 beds

(b) those of smaller size with under 100 beds

(c) the smallest units of 15 to 30 beds which functioned as hospital hostels.

In the 1950s there were five bureaux based on Bradford, Hull, Leeds, Wakefield and York. These were reduced to four in the ' 60 s by amalgamating Wakefield with Leeds which then served a population of 1,200,000. In 1972, when the brand new 480 bed Fieldhead Hospital was opened at Wakefield, a fifth bureau was recreated.

\section{The NHS reorganisation of 1974 established area health authorities}

These new authorities served areas which, by coincidence, were very similar to the areas covered by the pre-existing sub-regional admission bureaux. Only minor changes were needed to adjust the bureau areas to fit the area health authority boundaries.

The restructuring of the NHS in 1982 introduced district health authorities. This change was the beginning of the end for the bureau system. District based local community orientated services for mental handicap in each health district became the favoured ultimate ideal to be achieved.

Viewed in retrospect, the bureau system had obvious disadvantages on account of the extensive territory each bureau covered. The big conurbations of Leeds, with Meanwood Park Hospital, Bradford, with Westwood Hospital, and Wakefield, with Fieldhead Hospital, were served by mental handicap hospitals relatively near to their centres of population. Halifax was less well placed, although Westwood Hospital was not too inaccessible. Huddersfield was the least well served as it depended on Wakefield's Fieldhead Hospital.

The advantage of the bureau system was that over a large area it enabled some consistency, coordination and control of services to be achieved. It was also a convenient way of deploying cover from only a handful of consultants in mental handicap. The region delegated to each bureau the responsibility for its waiting list.

Many of the small hospitals were very isolated. The position in West Yorkshire compared advantageously with the Hull and York Bureaux, where the main mental handicap hospitals were several miles from city centres. The hospitals used a variety of buildings. They ranged through purpose-built mental deficiency hospitals, an inebriates' retreat, former mansions, agricultural hostels, workhouses, fever hospitals and a vicarage.

\section{Special needs provision}

The records of meetings of the consultant psychiatrists in the Yorkshire region show that a constantly recurring theme was the care of mentally handicapped people who were only mildly or moderately mentally retarded, but who had offended or presented seriously aggressive, violent or sexually deviant behaviours. In the ' 60 s the Regional Board designated special units for male and female patients 
respectively at Whixley Hospital, York, and Hatfield Hall Hospital, Wakefield.

In the '70s, it was decided that each service area should "consume its own smoke" by local provision for these cases. Their small number and special needs always made them a group difficult to provide for satisfactorily. The recent appointment to Leeds of a consultant and senior lecturer with a district responsibility to run a special needs service for this group of patients has reflected their continuing presence and is another attempt to meet their needs.

A unit for 'difficult to place patients', the DPPU, was opened at Fieldhead Hospital in the summer of 1985. This was associated with Newton Lodge, the new regional secure unit. Renamed the Heath Unit, the DPPU was brought under the control of a consultant in mental handicap in the autumn of 1986.

\section{The Association of Yorkshire Regional Consultants in Mental Handicap}

In the 1960s it was the custom for the consultant psychiatrists in mental handicap, or subnormality as it was then called, who were working within the Leeds hospital region, to meet at intervals with the medical officer on the staff of the regional headquarters who had a specific responsibility for the region's mental handicap services. These meetings were held regularly either in turn at the different mental handicap hospitals throughout the region, or at the regional headquarters in Harrogate. The meetings also afforded the consultants with welcome opportunity to meet each other and were much appreciated.

After the reorganisation of the National Health Service in April 1974, the system of regular meetings lapsed. A few ad hoc consultations were called at the regional headquarters. A psychiatric subcommittee of the regional medical committee was formed in 1975. The consultants in mental handicap have three seats on this committee.

From time to time the subcommittee considered matters relating to mental handicap. Some topics were constantly arising, such as consultant staffing and the recruitment of doctors to mental handicap, the appropriate care and placement of patients with disturbed behaviour and mental illness co-existing with mental handicap, the development of an academic department for the specialty and the future number of hospital beds needed for mental handicap. In 1985 the psychiatric subcommittee was reorganised and mental handicap no longer enjoyed a specified membership

In 1981 the Yorkshire regional consultants in mental handicap decided to form an association. Its inauguration reflected the wishes of the consultants to meet at regular intervals in privacy and informally to discuss matters of mutual interest and importance, to receive reports, to share experiences and to review changes and developments in the service generally. The need for such an association arose because no opportunity existed for consultants to meet among themselves to discuss and to comment on matters relating to mental handicap. The declared aim of the association was to provide a forum for discussion, debate and dialogue on mental handicap and associated subjects of interest and concern to the consultants in mental handicap working in the Yorkshire region. Membership of the association included all regional consultants in mental handicap.

\section{Senior registrar training in mental handicap}

In the Yorkshire region, a senior registrar post especially designed for training in mental handicap was established in October 1963. In the early '70s a second senior registrar post was created and in the mid-'80s a third post was introduced. Of 14 senior registrars in the scheme from 1963 up to December 1988, ten gained consultant posts, five of them in the Yorkshire region.

In the original scheme, the senior registrar was based at a large mental handicap hospital and participated in clinical and out-patient work. Each week four sessions were devoted to one or two assignments which lasted for periods of six months. These assignments embraced electroencephalography, forensic psychiatry, community mental health services and others of the trainee's choice, including research. For a time the doctors were expected to give a brief account of their assignments at the university department of psychiatry's weekly meetings.

\section{Consultant stafing}

In the early '60s, the Leeds/Yorkshire region had four consultants in mental handicap, designated medical superintendents, to cover 4,000 beds for mental handicap in 26 hospitals. The standard norm for provision was 1.3 beds per 1,000 of population. At one time the Leeds region had proposed 1.4 beds per 1,000 .

From the mid-'60s a programme of doubling the number of consultants in mental handicap began and this was achieved by the early '70s. Then additional appointments gave a third consultant to each of the two large service areas based on Leeds and Bradford. Two entirely new consultant posts were created for the new Fieldhead Hospital at Wakefield. By the mid-'70s the number of consultants in mental handicap in the Yorkshire region reached a peak of 12 fulltime appointments. This fortunate state of affairs was soon to change as a result of five retirals over 
three years. Consultant staffing entered a critical phase.

There was increasing uncertainty nationally about the future direction of mental handicap services. Some health authorities became noticeably slow to fill consultant vacancies in mental handicap. Hospital bed numbers for mental handicap in the Yorkshire region had risen to a peak of 4,068 in 1966 and then fallen, with 3,872 in $1973,3,642$ in 1976, 3,450 in 1980, 3,125 in 1983, and 2,503 in 1986.

As the hospitals were running down it was thought that fewer consultants would be needed. The fallacy of such claims was later realised. Because there were fewer mentally handicapped people in hospitals it did not mean that the number of mentally handicapped people in the population was any less than it had been. Maintaining mentally handicapped people in the community often calls for more time and attention than keeping them in a hospital ward.

Health authorities tended to assume that a shortage of suitable candidates for consultant posts in mental handicap was a reason for not advertising them. In practice the posts that were advertised were eventually filled. Delays resulted in two senior registrars who had trained for three years in the region obtaining consultant appointments outside Yorkshire.
A move towards more flexible staffing began in 1983 with a joint post in mental illness and mental handicap at Huddersfield. Consultant posts combining three sessions in mental handicap with mental illness were introduced for Calderdale in 1987 and Harrogate in 1988. Full-time vacancies were filled at Pontefract in 1983, York in 1984, and Hull in 1988. After much discussion and procrastination a consultant post with five service sessions and five sessions as senior lecturer in mental handicap was finally filled at Leeds in 1987.

In November 1988 the Yorkshire region had eight full-time posts, one joint appointment and two special interest posts in mental handicap. Leeds and Bradford had fewer consultants than a decade ago. A third consultant post, full-time, is promised for West Leeds. More joint and special interest appointments are likely to be seen in districts with less than 200,000 population.

Where there is only one specialist to cover mental handicap in a health district the consultant might have a feeling of working in isolation. The need to have opportunities for consultants in mental handicap to keep in touch with their colleagues will continue to be important in the future. The presence of a regional association is one way of meeting this need.

\title{
Foreign report
}

\section{Psychiatry in Canada}

\author{
SidNEy KenNEDy, Department of Psychiatry, Toronto General Hospital, Toronto, \\ Ontario, Canada
}

There are two episodes which remain in my mind from the first night I was on call at the Clarke Institute of Psychiatry, Toronto in 1980 . The first person I assessed in the Emergency Room was a young university student in her early twenties who had been reading "Jung" and urgently needed to discuss "archetypes and the animus"; the second incident some hours later involved a middle aged man who was manic on admission and responded rapidly to the $10 \mathrm{mg}$ of haloperidol I administered intravenously in front of a silent and, as I later discovered, astonished night nurse and junior resident. The patient settled rapidly and my unorthodox treatment was a talking point for several weeks. These two vignettes alerted me to the fact that things were different here. No-one had ever used intravenous neuroleptics in Toronto at that time, and equally no-one in Newcastle on Tyne, which I had left only two weeks earlier, would consider the casualty department of the Royal 